\title{
Counter-traction using clips and rubber banding for endoscopic submucosal dissection of a laterally spreading tumor involving a diverticulum in the colon
}

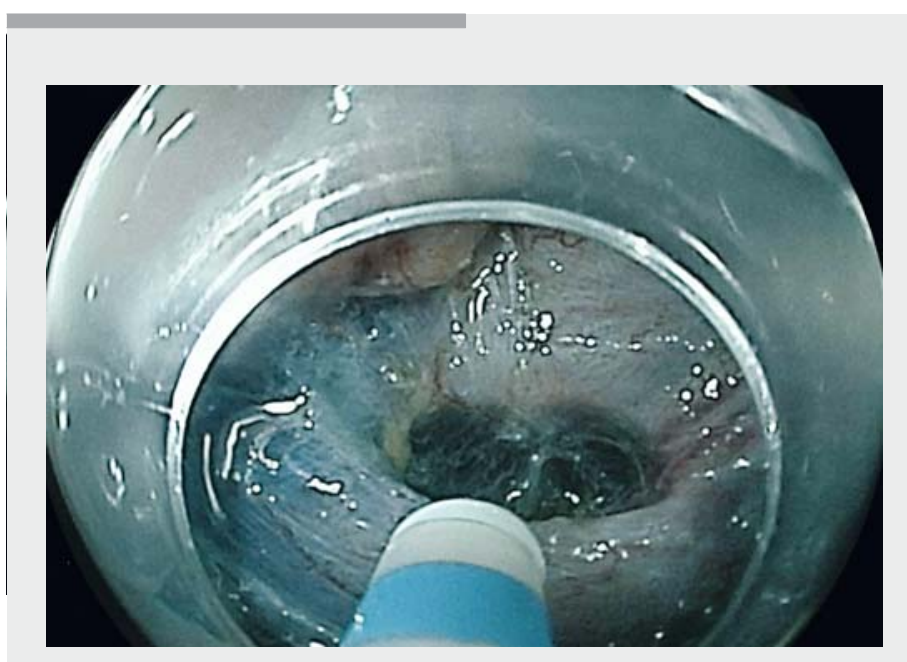

Video 1 Counter-traction using clips and rubber banding for endoscopic submucosal dissection of a laterally spreading tumor involving a diverticulum in the colon.

In addition to the possibility of en bloc resection without size limitations, endoscopic submucosal dissection (ESD) is also a novel option for endoscopic treatment of lesions involving a diverticulum in the colon [1] or appendix [2]. Generally, when employing endoscopic mucosal resection, these types of lesions have a high risk of perforation or incomplete resection.

Here, we report a case of a laterally spreading tumor (LST) involving a colonic diverticulum that underwent successful en bloc resection by ESD using counter-traction with clips and rubber banding ( $>$ Video 1).

A man in his 60 s was referred to our hospital for resection of a $40-\mathrm{mm}$ LST in the ascending colon ( $>$ Fig. 1 ). It was a granular LST with a regular vascular and pit pattern on blue-laser imaging but also involvement of a centrally located diverticulum, all of which were indications for ESD.

After the initial needle injection, ESD was initiated from the anal side using the DualKnife J (Olympus Medical, Tokyo, Japan) injecting glycerol mixture. We used counter-traction with clips and rubber bands ( $>$ Fig. 2) to allow better exposure of the submucosal layer, as described previously [3]. Once the endoscope approached the diverticulum, a second traction using two clips and another rubber band was positioned to allow a maximal increase in the submucosal space. ESD was performed cautiously in the area of the diverticulum, and the location of the submucosal plane was determined by counter-traction. After dissection, we found an accumulation of "submucosal" fibers at the base of the diverticulum that were not perforated ( $>$ Fig. 3 ). Finally, en bloc resection was completed in 50 minutes, and the diverticulum was closed to prevent delayed perforation. The patient was discharged without complications 24 hours later.

Pathological analysis revealed a tubulovillous adenoma measuring $52 \times 40 \mathrm{~mm}$, with high grade dysplasia and free margins.

Our proposed counter-traction technique using clips and rubber banding allows en bloc resection of large colonic adenomas involving diverticula, which

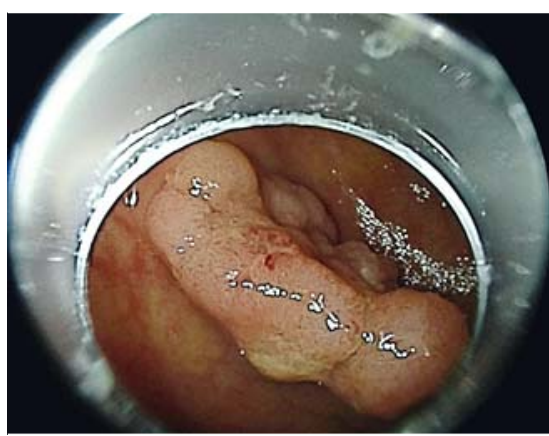

- Fig. 1 A 40-mm laterally spreading tumor in the ascending colon with central diverticulum.

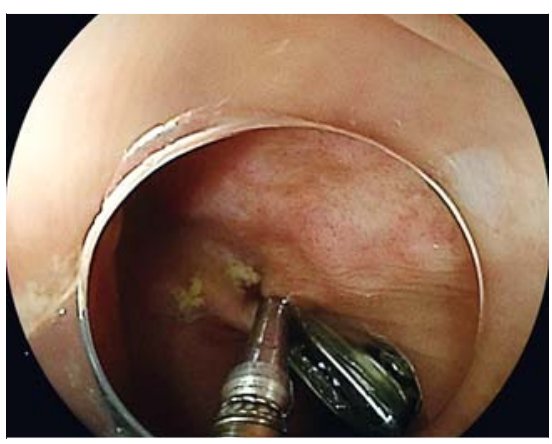

- Fig. 2 Setting up a counter-traction by clips and rubber band.

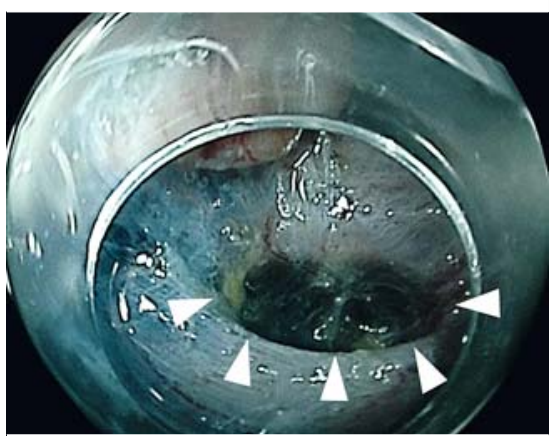

- Fig. 3 Diverticular area (arrows) after endoscopic submucosal dissection.

would normally be treated by surgery or a full-thickness resection device.

Endoscopy_UCTN_Code_TTT_1AQ_2AD 
None

The authors

Jérémie Albouys ${ }^{1}$, Sophie Geyl ${ }^{1}$, Aurélie Charissoux ${ }^{2}$, Romain Legros ${ }^{1}$, Denis Sautereau ${ }^{1}$, Mathieu Pioche ${ }^{3}$, Jérémie Jacques ${ }^{1}$

1 Gastroentérologie et endoscopie digestive, CHU Dupuytren, Limoges, France

2 Anatomopathologie, CHU Dupuytren, Limoges, France

3 Unité d'endoscopie digestive, Service de Gastroentérologie - pavillon H, Hôpital Edouard Herriot, Hospices Civils de Lyon, Lyon, France

\section{Jérémie Jacques, MD}

Service d'Hépato-gastro-entérologie, $\mathrm{CHU}$ Dupuytren, 2 avenue Martin Luther-King, 87042 Limoges, France

Fax: +33-5-55058733

jeremiejacques@gmail.com

\section{References}

[1] Kato M, Uraoka T, Wada M et al. Laterally spreading tumor involving a colon diverticulum successfully resected by endoscopic submucosal dissection. Gastrointest Endosc 2016; 84: 191 - 192

[2] Utzeri E, Jacques ], Charissoux A et al. Traction strategy with clips and rubber band allows complete en bloc endoscopic submucosal dissection of laterally spreading tumors invading the appendix. Endoscopy 2017; 49: 820 - 822

[3] Jacques ], Charissoux A, Legros R et al. Double-clip counter-traction using a rubber band is a useful and adaptive tool for colonic endoscopic submucosal dissection. Endoscopy 2018; 50: 179-181

\section{Bibliography}

DOI https://doi.org/10.1055/a-0915-1463

Published online: 23.5.2019

Endoscopy 2019; 51: E295-E296

(c) Georg Thieme Verlag KG

Stuttgart · New York

ISSN 0013-726X

\section{ENDOSCOPY E-VIDEOS}

https://eref.thieme.de/e-videos

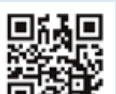

Endoscopy E-Videos is a free access online section, reporting on interesting cases and new

techniques in gastroenterological endoscopy. All papers include a high quality video and all contributions are freely accessible online.

This section has its own submission website at https://mc.manuscriptcentral.com/e-videos 